\title{
Factors Affecting Adherence to Insulin Therapy among Patients with Type 2 Diabetes Mellitus in a Selected Teaching Hospital, Sri Lanka
}

\author{
Lashani Navodya Weerakoon ${ }^{1}$, Thamara Dilhani Amarasekara ${ }^{2 *}$ and Rasika Jayasekara ${ }^{3}$ \\ ${ }^{1}$ Health and Social Care Teacher, Senarath Paranavithana National School, Udugampola, Sri Lanka \\ ${ }^{2}$ Senior Lecturer in Nursing, Department of Nursing and Midwifery, Faculty of Allied Health Sciences,University of Sri Jayewardenepura, \\ Sri Lanka \\ ${ }^{3}$ Senior Lecturer in Nursing \& Midwifery, UniSA Clinical \& Health Sciences, University of South Australia, South Australia \\ *Corresponding author: Thamara Dilhani Amarasekara, Senior Lecturer in Nursing, Department of Nursing and Midwifery, Faculty \\ of Allied Health Sciences, University of Sri Jayewardenepura, Sri Lanka
}

\section{ARTICLE INFO \\ Received: September 10, 2020 \\ Published: 慧 September 23, 2020}

Citation: Lashani Navodya Weerakoon, Thamara Dilhani Amarasekara, Rasika Jayasekara. Factors Affecting Adherence to Insulin Therapy among Patients with Type 2 Diabetes Mellitus in a Selected Teaching Hospital, Sri Lanka. Biomed J Sci \& Tech Res 30(4)-2020. BJSTR. MS.ID.004990.

Keywords: Adherence; Non-Adherence; Insulin Therapy; T2DM; Sri Lanka

\section{ABSTRACT}

Objective: In recent decades, the prevalence of type 2 Diabetes Mellitus (T2DM) has increased significantly worldwide, including Sri Lanka. Insulin therapy is essential pharmacological management of T2DM. Studies conducted on adherence to insulin therapy among patients with T2DM are few in Sri Lanka; therefore, this study was conducted.

Methods: Descriptive cross-sectional design was used with purposively selected 252 patients with T2DM who were admitted to the Colombo South Teaching Hospital (CSTH) during the study period.A pre-tested interviewer-administered questionnaire and 8-Item Morisky Medication Adherence Scale were used to collect data and analyzed by using descriptive statistics. Ethical approval was obtained from the Ethics Review Committees of Faculty of Medical Sciences, University of Sri Jayawardenapura and CSTH.

Key Findings: From all participants, 135 (53.6\%) were males, and 117(46.4\%) were females. Mean age was 60.37 years. The overall adherence rate was $42.5 \%$, and nonadherence rate was $57.5 \%$.There is a significant association ( $p>0.05)$ between adherence and age, gender, educational level, financial problem, knowing about the complications, stress or emotional problems, challenging to take insulin at the same time the same day, skipping meals and taking drugs for other diseases.

Conclusion: Adherence to insulin therapy is less due to inadequate patients' awareness. Therefore, health care providers should provide effective and tailored health education to enhance adherence to recommended insulin therapy among adults with T2DM in Sri Lanka.

\section{Introduction}

\section{Background}

Non Communicable Diseases are a significant burden to the world at present. Diabetes Mellitus (DM) plays a significant role among them, as it is one of four priority non-communicable diseases targeted action in the world [1]. DM is the 3rd cause for deaths in Sri Lanka [2]. The national prevalence of diabetes is 10.3\%, and it will be $13.9 \%$ in 2030 in Sri Lanka [3]. In 2011 the prevalence of DM was $18.6 \%$ in the western province, and it was the highest prevalence of DM in Sri Lanka [4]. Glycemic control is the key management strategy to prevent DM complications. Glycemic control can be managed by mainly using lifestyle modifications 
such as diet control and regular exercise.However, when these are not enough to control glycemic levels; pharmacological management -oral anti-hyperglycemic drugs and insulin are used. The prevalence of DM and its related complications are high in Sri Lanka. The majority of the patients with DM receive health care on free of charge; however, adherence to health care advises regarding DM management are inadequate; therefore, the-glycemic control is poor in Sri Lanka [5,6]. Studies on adherence to insulin therapy among patients with T2DM are very few in Sri Lanka.

\section{Literature Review}

In the 21st century, DM is a global health emergency [7] Every year more and more new patients reported with DM. Still, many countries are unaware of the social and economic impact of DM. Therefore, there is an urgent need to control the prevalence of DM, and proper management of DM complications is also essential. Diabetes is a metabolic disorder of multiple etiological characterized by chronic hyperglycemia with disturbances of carbohydrate, fat and protein metabolism resulting from defects in insulin secretion, the action of insulin or both [8]. There are mainly three types of DM such as Type 1 DM, Type 2 DM and Gestational Diabetes; however, the majority of patients (90\%) are T2DM [9]. Diabetes can be treated and managed with a healthy diet, regular physical exercises and adherence to medications to reduce elevated blood glucose level [10]. Patient education and self-care practices also are important aspects of DM management which help patients with diabetes to minimize complications and stay healthy.

An internet survey was conducted among 1250 physicians (600 specialists, 650 primary care physicians) who treat patients with DM and also telephone survey has been conducted with 1530 insulin-treated patients (180 with T1DM, 1350 with T2DM) in China,France, Japan, Germany, Spain, Turkey, UK and USA The purpose of the study was to examine patient and physician beliefs regarding insulin therapy and the degree to which patients adhere to their insulin regimens. Results of their study show that patients and care providers indicated the same five most common reasons for insulin omission/non-adherence such as too busy; travelling; skipped meals; stress / emotional problems and public embarrassment [11]. A cross-sectional study was carried out to determine adherence to treatment among patients with T2DM visiting a tertiary care hospital in Bangalore defined adherence as patients having never missed their medications in the past one month before the interview by them. Data was collected through an interviewer-administered structured questionnaire from 300 patients.

This study showed $71.3 \%$ were adherent to the medication treatment, while $28.7 \%$ were non -adherent[12].Among the reasons for non-adherence, lack of availability was evident in the majority (30\%) while lack of motivation, fear of side effects, need to travel long distances for follow up were other important reasons
[12]. Another cross-sectional study was carried out in Iran with use of 507 conveniently selected sample to evaluate adherence to insulin therapy among patients with T1DM or T2DM, the underlying factors affecting insulin injection omission among patients with T1DM or T2DM were also investigated [13]. This study has been undertaken in Endocrinology and Metabolism Research Center outpatient diabetes clinic, affiliated to Tehran University of Medical Sciences. Adherence to insulin therapy was measured by using the 8-Item Morisky Medication Adherence Scale (MMS) and the auto compliance method. (The auto compliance test estimates the number of skipped insulin injections during the previous month).

This study has shown that $14.3 \%$ and $28.8 \%$ of patients with T1DM and T2DMhad low adherence to insulin therapy. Patients with T1DM show more adherence because they understand the importance of having insulin and life-threatening events compared to patients with T2DM [13].A cross-sectional study of glycemic control among adults with T2DMshows more than half, $61.7 \%$ of patients with T2DM did not do any exercise, more than one third had not to do diet control (38.4\%) and not take medication regularly (37\%) in a large teaching hospital and a primary care unit in Colombo, Sri Lanka [6]. The findings outlined that the majority of adults with T2DM in this study did not achieve desired glycemic control. It is clear that there is an urgent need to provide improved health education for patients with T2DM in Sri Lanka to reduce the complications associated with uncontrolled glycemia, and which involves appropriate diet control, adoption of regular exercise regimen, adherence to medication, and how a person's health behaviors affect glycemic control.

Health professionals in Sri Lanka need to understand better the glycemic control behaviors of their patients with T2DM. The health education is given in a proper and culturally-appropriate way to improve patients' adherence behaviors, health, and wellbeing.According to the above studies, the prevalence of T2DM and related complications are high in Sri Lanka; however, data related to adherence to insulin therapy among adults with T2DM are limited. Therefore, it is essential to assess the factors affecting adherence to insulin therapy among patients with T2DMin Sri Lanka. This study aimed to determine factors affecting adherence to insulin therapy among patients with T2DM admitted to a selected Teaching Hospital in Sri Lanka. Identifying those factors are more significant to find solutions/strategies to improve their adherence to insulin therapy. Then the prevalence of complications related to DM will reduce among patients with T2DM in Sri Lanka.

\section{Methods}

\section{Design and Setting}

The study followed a descriptive, quantitative, cross-sectional design. The study was conducted in the medical and surgical wards in CSTH, Sri Lanka. 


\section{Population and Sample}

The study population included patients with T2DM admitted to the CSTH during the study period and who started insulin therapy for at least six months before they admit to the hospital. This is because patients need some time to adhere to insulin therapy; a convenience sampling method was used to select 252 patients with T2DM in above wards. The patients in the critical stage and patients who were unable to understand either Sinhala or English languages were excluded.

\section{Data Collection}

A pre-tested an interviewer-administered questionnaire and the eight-item Morisky Medication Adherence Scale were used to collect data from participants who consent to participate without disturbing to their hospital care. This questionnaire can be completed within 20 minutes. The data collection instrument was developed by the researchers based on extensive and intensive literature. It included three (3) Sections; Part I- included patient's information (Including age, gender, occupation, educational level, etc.), Part II- included Morisky Medication Adherence Scale. An eight-item Morisky Medication adherence questionnaire was used to assess medication adherence. Patients responded yes (1-mark) or no (0-mark) to each of the questions. Based on the scores obtained, 0 was considered high adherence, 1 or 2 as medium adherence and $>2$ was low adherence. In this study, medium and high adherence were considered as adherent and low adherence as non-adherent for statistical purpose, Part III- included questions about factors affecting Adherence/ Non-adherence to insulin therapy. The questionnaire was initially created in English, and subsequently is was translated to Sinhala which is the most commonly used language in Sri Lanka. The questionnaire was pre-tested among 15 patients with T2DM to determine acceptability, feasibility, comprehensibility and appropriateness. These 15 participants did not participate in the main study.

\section{Data Analysis}

Sample characteristics was analysed by using descriptive statistics, by using SPSS 16 version statistical packages and Chi square test use to find association. Mean value was used to divide continuous variables into two sections. As examples

- age (mean value 60.37)

$>60$ years.

$\leq 60$ years.

Socio-demographic data also used as factors affecting to adherence.

\section{Ethical Considerations}

Ethical approval was obtained from the Ethics Review Committees of the Faculty of Medical Sciences, University of Sri Jayewardenepura, Sri Lanka and CSTH, Sri Lanka and further permission was obtained from the relevant authorities. Privacy and the confidentiality of the participants were ensured at every stage of the study. The convenient time for participants was used for data collection after explained about the study with the information sheet, and all the information was gathered by anonymously after getting their written informed consent. All the methods followed were non- invasive. The data from the study was available only to the researcher and supervisor. Only the analyzed data were exposed to present in scientific communications.

\section{Results}

As shown in Table 1, a total of 252 patients with T2DM participated in this study. More than half of them (77.0\%) were in the age group 50 years to 70 years $(n=194)$ while the mean age was 60.37 years. Approximately half $(53.6 \%)$ of the participants were male $(n=135)$, and the other half $(46.4 \%)$ was female $(n=117)$. All most all participants (93.7\%) were married (Table 1).More than half of participants $142(56.3 \%)$ had T2DM for five years to 15 years. Majority of participants 216 (85.7\%) had been taking insulin for less than five years, and less amount of participants 36 (14.3\%) had been taking insulin for more than five years. Most of participants $191(75.8 \%)$ had a family history ofDiabetes.All most all are (83.7\%) use syringe to inject the insulin. The overall prevalence of adherence to insulin therapy was $42.5 \%$ (n=107)as a score of the eight itemsMorisky medication adherence scale was $\leq 2$ marks and prevalence of non- adherence to insulin therapy was $57.5 \%(n=145)$ as a score of the eight itemsMorisky medication adherence scale was $>2$ marks.

Table 1: Socio-demographic characteristics of the participants $(n=252)$.

\begin{tabular}{|c|c|c|}
\hline $\begin{array}{l}\text { Socio-Demographic } \\
\text { Characteristics }\end{array}$ & Frequency(n) & Percentage(\%) \\
\hline \multicolumn{3}{|l|}{ Age } \\
\hline$<50$ years & 26 & 10.3 \\
\hline 50-70 years & 194 & 77.0 \\
\hline$>70$ years & 32 & 12.7 \\
\hline \multicolumn{3}{|l|}{ Gender } \\
\hline Male & 135 & 53.6 \\
\hline Female & 117 & 46.4 \\
\hline \multicolumn{3}{|l|}{ Marital Status } \\
\hline Unmarried & 16 & 6.3 \\
\hline Married & 236 & 93.7 \\
\hline \multicolumn{3}{|l|}{ Educational Level } \\
\hline Up-tograde 5 & 74 & 29.4 \\
\hline Up-to O/L & 116 & 46.0 \\
\hline Up-to A/L & 46 & 18.3 \\
\hline Diploma & 13 & 5.2 \\
\hline Graduate & 3 & 1.2 \\
\hline \multicolumn{3}{|l|}{ Occupation } \\
\hline Yes & 158 & 62.7 \\
\hline
\end{tabular}




\begin{tabular}{|c|c|c|}
\hline No & 49 & 37.3 \\
\hline \multicolumn{3}{|l|}{} \\
\hline Monthly Income (Rs.) & 19 & 7.5 \\
\hline $5,001-10,000$ & 43 & 17.1 \\
\hline $10,001-20,000$ & 87 & 34.5 \\
\hline $20,001-50,000$ & 90 & 35.7 \\
\hline$<50,000$ & 13 & 5.2 \\
\hline
\end{tabular}

Table 2 shows that there were significant associations $(\mathrm{p}<0.050)$ between adherence and forget to take medication, unable to take insulin because of other reason, cutback or stopped taking insulin because of felt worse, Forget to bring along insulin when travelling, stop taking insulin when symptoms are under controlled and Feel hassled about sticking to the treatment regimen (Table 2).As shown in Table 3 being $\leq 60$ years, females, educated below ordinary level, having financial problem in buying medicine, knowing about the complication occurs due to non-adherence, having physical disabilities or chronic diseases and having any stress or emotional problems, having visual disturbances, hypertension, hyperlipidaemia, cardiovascular lead to being non-adherence (Table 3).

Table 2: Distribution of factors included in the Morisky Medication adherence scale associated with adherence and non-adherence $(n=252)$.

\begin{tabular}{|c|c|c|c|c|c|c|c|}
\hline \multirow{2}{*}{ Factors } & \multicolumn{2}{|c|}{ Adherence } & \multicolumn{2}{|c|}{ Non-Adherence } & \multirow{2}{*}{ P-value } & \multirow{2}{*}{ Odds Ratio } & \multirow{2}{*}{$(95 \%) \mathrm{CI}$} \\
\hline & n & $(\%)$ & n & (\%) & & & \\
\hline \multicolumn{8}{|c|}{ Forget to take Insulin } \\
\hline Yes & 4 & $(3.5)$ & 109 & $(96.5)$ & $0.000^{*}$ & 0.013 & $0.004-0.037$ \\
\hline No & 103 & $(74.1)$ & 36 & $(25.9)$ & & & \\
\hline \multicolumn{8}{|c|}{ Did not take Insulin because of Other Reason } \\
\hline Yes & 31 & $(28.9)$ & 76 & (71.1) & 0.000 & 0.184 & 0.106-0.317 \\
\hline No & 100 & $(68.9)$ & 45 & $(31.1)$ & & & \\
\hline \multicolumn{8}{|c|}{ Cutback or Stopped taking Insulin because of Felt Worse } \\
\hline Yes & 3 & $(6.5)$ & 43 & $(93.5)$ & $0.000^{*}$ & 0.068 & $0.021-0.228$ \\
\hline No & 104 & $(50.5)$ & 102 & $(49.5)$ & & & \\
\hline \multicolumn{8}{|c|}{ Forget to bring along Insulin when Travelling } \\
\hline Yes & 37 & $(23.1)$ & 123 & $(76.9)$ & 0.000 & 0.095 & $0.052-0.173$ \\
\hline No & 70 & $(70.1)$ & 22 & $(23.9)$ & & & \\
\hline \multicolumn{8}{|c|}{ TakeInsulin Yesterday as Prescribed } \\
\hline Yes & 103 & $(41.5)$ & 145 & $(58.5)$ & $0.031^{*}$ & & $0.927-0.999$ \\
\hline No & 4 & $(100)$ & 0 & $(0.0)$ & & & \\
\hline \multicolumn{8}{|c|}{ Stop taking Insulin when Symptoms are Under Controlled } \\
\hline Yes & 3 & $(10.7)$ & 25 & $(89.3)$ & $0.000^{*}$ & 0.138 & 0.041-0.472 \\
\hline No & 104 & $(46.4)$ & 120 & $(53.6)$ & & & \\
\hline \multicolumn{8}{|c|}{ Feel Hassled about Sticking to the Treatment Regimen } \\
\hline Yes & 49 & $(26.3)$ & 137 & $(73.7)$ & 0.000 & 0.049 & $0.022-0.111$ \\
\hline No & 58 & $(87.9)$ & 8 & $(12.1)$ & & & \\
\hline
\end{tabular}

${ }^{*} \mathrm{p}$ Value derived from Fisher's Exact test

Table 3: Other Factors associated with adherence and non-adherence $(n=252)$.

\begin{tabular}{|c|c|c|c|c|c|c|c|}
\hline \multirow{2}{*}{ Factors } & \multicolumn{2}{|c|}{ Adherence } & \multicolumn{2}{|c|}{ Non-Adherence } & \multirow{2}{*}{ P-value } & \multirow{2}{*}{ Odds ratio } & \multirow{2}{*}{ (95\%) CI } \\
\hline & $\mathrm{n}$ & (\%) & $\mathrm{n}$ & (\%) & & & \\
\hline \multicolumn{8}{|c|}{ Age } \\
\hline$\leq 60$ years & 47 & $(36.2)$ & 83 & $(63.8)$ & 0.037 & 0.585 & $0.037-0.969$ \\
\hline$>60$ years & 60 & $(49.2)$ & 62 & $(50.8)$ & & & \\
\hline \multicolumn{8}{|c|}{ Gender } \\
\hline Male & 68 & $(50.4)$ & 67 & $(49.6)$ & 0.006 & 2.030 & $1.217-3.385$ \\
\hline Female & 39 & (33.3) & 78 & $(66.7)$ & & & \\
\hline \multicolumn{8}{|c|}{ Education } \\
\hline$<0 / L$ & 19 & $(25.7)$ & 55 & (74.3) & 0.001 & 0.353 & $0.194-0.643$ \\
\hline$\geq 0 / L$ & 88 & $(49.4)$ & 90 & $(50.6)$ & & & \\
\hline
\end{tabular}




\begin{tabular}{|c|c|c|c|c|c|c|c|}
\hline \multicolumn{8}{|c|}{ Have a Financial Problem in Buying Medicine } \\
\hline Yes & 16 & $(19.8)$ & 65 & $(80.2)$ & 0.000 & 0.261 & $0.116-0.404$ \\
\hline No & 91 & $(53.2)$ & 80 & $(46.8)$ & & & \\
\hline \multicolumn{8}{|c|}{ Know about Complications } \\
\hline Yes & 89 & $(53.3)$ & 78 & $(46.7)$ & 0.000 & 4.247 & $2.325-7.759$ \\
\hline No & 18 & $(21.2)$ & 67 & $(78.8)$ & & & \\
\hline \multicolumn{8}{|c|}{ Have any Stress or Emotional Problems } \\
\hline Yes & 18 & $(18.4)$ & 80 & $(81.6)$ & 0.000 & 0.164 & $0.090-0.300$ \\
\hline No & 89 & $(57.8)$ & 65 & $(42.2)$ & & & \\
\hline \multicolumn{8}{|c|}{ Challenging to take Insulin at the Same Time Every Day } \\
\hline Yes & 41 & $(26.8)$ & 112 & $(73.2)$ & 0.000 & 0.183 & $0.106-0.317$ \\
\hline No & 66 & $(66.7)$ & 33 & $(33.3)$ & & & \\
\hline \multicolumn{8}{|c|}{ Do You Skip Meals } \\
\hline Yes & 31 & $(26.5)$ & 86 & $(73.5)$ & 0.000 & 0.280 & $0.164-0.477$ \\
\hline No & 76 & $(56.3)$ & 59 & $(43.7)$ & & & \\
\hline \multicolumn{8}{|c|}{ Drugs for Other Diseases } \\
\hline Yes & 66 & $(37.9)$ & 108 & $(62.1)$ & 0.030 & 0.551 & $0.321-0.946$ \\
\hline No & 41 & $(52.6)$ & 37 & $(47.4)$ & & & \\
\hline
\end{tabular}

\section{Discussion}

This study indicated that according to the eight items Morisky medication adherence scale, more than half of the participants $145(57.5 \%)$ were non-adherent to insulin therapy while only 107 ( $42.5 \%$ ) were adherent. In Iran, patients with T2DM ( $n=507)$, $24.9 \%$ were highly adherent to insulin injections whereas, $46.3 \%$ and $28.8 \%$ of them were considered to have medium and low adherence to insulin therapy [13]. In this study, there is a significant association between "forget to take insulin" and adherence, according to Fisher's exact test $(\mathrm{p}=0.000)$. A study was conducted in Iran to evaluate adherence to insulin therapy in patients with diabetes and underlying factors affecting insulin injection omission among patients with T1DM, or T2DMwas showed that there was a significant association $(\mathrm{p}<0.01)$ between forgetfulness and adherence to insulin therapy [13].

In the current study, a significant association between "unable to take insulin because of other reasons (except forgetfulness)" and adherence $(\mathrm{p}=0.000)$. More than half of non-adherents $(71.1 \%)$ were unable to take insulin because of other reasons while nearly $30 \%$ (31) of adherents unable to take insulin because of other reasons.

In the present study shows a significant relationship $(\mathrm{p}=0.000)$ between "cutback or stopped taking insulin because of felt worse". The majority 43 (93.5\%) participants who cut back or stopped taking insulin because of felt worse were non-adherents. The similar study was done in Iran also showed that there was a significant association $(\mathrm{p}<0.01)$ between Feeling worse after insulin injection with adherence [13].In this study "Forget to bring along insulin when travelling", and adherence shows a significant relationship $(p=0.001)$. The majority $(76.9 \%)$ of subjects who had forgotten to bring along insulin when travelling were non-adherents. Also, there was a significant association between "stop taking insulin when symptoms are under controlled" and adherence $(p=0.000)$. Majority of the participants (89.3\%) who stop taking insulin when symptoms are under controlled were non-adherents. While feel hassled about sticking to the treatment regimen and adherence has shown a significant association $(\mathrm{p}=0.000)$, the majority $(73.7 \%)$ of patients who think hassled about sticking to treatment regimen were non- adherents. According to the present study presence of all the above factors affect the non-adherence to the insulin therapy of patients with T2DM.

In this study, there is a significant association $(\mathrm{p}=0.037)$ between age (divided into two groups using mean age) and adherence. Most of $\leq 60$ years (63.8\%) are more prone to nonadhere to insulin therapy. A study was done in Turkey to assess adherence to insulin treatment in insulin type 2 diabetic patients initiated on different insulin regimens also showed that there was a significant association between age and adherence $(p=0.001)$ and most younger patients were non-adhere [14]. This study shows a significant association $(\mathrm{p}=0.006)$ between gender and adherence. More than half of the non-adherents 78 (66.7\%) were females. A similar study done in Iran showed that there was no significant association $(\mathrm{p}=0.86)$ between gender and adherence to insulin, but adherence among males (64\%) was higher than adherence among females [13], and another study in the USAalso showed that female gender associated with the non-adherence [15]. The majority (74.3\%) of non-adherents educational level was below the ordinary level (Garde 10), so there is a risk of being non-adherence with the level of education. In this study, there is a significant relationship between educational level (above Grade 10) and adherence $(\mathrm{p}=0.001)$. 
Interestingly an internet survey conducted in the USA showed that participants with the highest level of education were non- adherence to insulin therapy ( $p \leq 0.03$ ) [16].A significant association was shown between the financial problem of buying medicine and adherence $(p=0.000)$. Most participants $(80.2 \%)$ were non-adherents who had that financial issues. The limited financial situation in buying medicine is the cause of being nonadherence. Other studies also showed that financial problems affect adherence. In Iran, there was a significant association ( $p=0.01$ ) between cost and adherence [13]. The internet survey also showed that participants who had a higher level of income were adherence to insulin therapy $(p \leq 0.02)[16]$.When the participants know about the complication occurs due to non-adherence, they may adhere to the insulin therapy and participants who do not know about it more prone to non-adhere. In this study, there is a significant association $(p=0.000)$ between know about complications and adherence.

More than half of (53.3\%) of participants know about complications were adherence while the majority $(78.8 \%)$ of participants who do not know about the complications of DM were non-adherents. Most participants, 80 (81.6\%) who are having any stress or emotional problems were non-adherents, and it has a significant association $(\mathrm{p}=0.0000)$. The internet survey done in China, France, Japan, Germany, Spain, Turkey, the UK or the USA showed that $9.4 \%$ participants who had the challenge to take insulin at the same time the same day, reported insulin nonadherence [11]. In the present study, participants who skip meals were non-adherent $(73.5 \%)(\mathrm{p}=0.000)$, but another study showed that skip meals cause to only $15 \%$ of non-adherence [11]. Also, approximately $2 / 3$ subjects $(62.1 \%)$ who take medications for their other diseases except diabetes were non-adherents, and there is a significant association $(\mathrm{p}=0.030)$. There are a few limitations in this study. Only one hospital selected to collect data; therefore, findings cannot be generalized to the broader population. Another limitation was the convenience sampling method used to determine the sample.

\section{Conclusion}

The study findings showed that according to Morisky medication adherence scale forget to take medication, unable to take insulin because of other reason, cutback or stopped taking insulin because of felt worse, fail to bring along insulin when travelling, stop taking insulin when symptoms are under controlled and Feel hassled about sticking to treatment regimen had significant association $(\mathrm{p}<0.05)$ with non-adherence. Other associated factors like being $\leq 60$ years, female gender, educated below ordinary level, having financial problem in buying medicine, do not know about the complications occurs due to non-adherence, having physical disabilities or chronic diseases and having any stress or emotional problems also lead to being non-adherence. Patients' knowledge of diabetes is a crucial factor in determining their adherence to medication and diabetes management. Finally, it can be suggested that health care providers should provide more effective health education interventions to enhance insulin adherence among patients with T2DM and more research should be conducted to identify the factors affecting the adherence/non-adherence to the insulin therapy among patients with T2DM.

\section{Conflicts of Interest}

All contributing authors declare no conflicts of interest.

\section{References}

1. (2016) World Health Organization. Global report on diabetes.

2. (2015) WHO statistics profile Sri Lanka.

3. Katulanda P, Constantine GR, Mahesh JG, Sheriff R, Seneviratne RDA, et al. (2008) Prevalence and projections of diabetes and pre-diabetes in adults in Sri Lanka. Diabet Med 25(9): 1062-1090.

4. Katulanda P, Rathnapala DAV, Sheriff R, Matthews DR (2011) Province and ethnic-specific prevalence of diabetes among Sri Lankan adults. Sri Lanka Journal of Diabetes Endocrinology and Metabolism 1: 2-7.

5. (2015) Diabetes management. Wikipedia, the free encyclopedia.

6. Amarasekara AATD, Fongkaew W, Wimalasekera SW, Turale S, Chanprasit C (2015) A cross-sectional study of glycemic control among adults with type 2 diabetes Glycemic control in type 2 diabetes. Nursing and Health Sciences 17(2): 223-228.

7. (2015) International Diabetes Federation DIABETES ATLAS Seventh Edition.

8. (1999) World Health Organization. Definition, diagnosis and classification of diabetes mellitus and its complications: report of a WHO consultation. Part 1, Diagnosis and classification of diabetes mellitus.

9. WHO (2016) World Health Day.

10. (2014) USA National Diabetes Statistics Report.

11. Peyrot M, Barnett AH, Meneghini LF, Schumm Draeger PM (2012) Global Attitudes of Patients and Physicians in Insulin Therapy study. Diabet Med 29(5): 682-689.

12. Banu S, Prasanth YM, Anjana K (2014) Adherence to treatment among type 2 diabetes mellitus patients visiting a tertiary care hospital in Mangalore Department of Medicine, Father Muller Medical College, Mangalore, Karnataka, India. International Journal of Biomedical Research.

13. Farsaeia S, Radfarb M, Heydaric Z, Abbasic F, Qorbanie M (2014) Insulin adherence in patients with diabetes: Risk factors for injection omission, Prim Care Diabetes 8(4): 338-345.

14. Yavuz DGG, Ozcan S, Deyneli O (2015) Adherence to insulin treatment in insulin-naïve type 2 diabetic patients initiated on different insulin regimens. Patient Prefer Adherence 9: 1225-1231.

15. Bains SS, Egede LE (2011) Associations between health literacy, diabetes knowledge, self-care behaviors, and glycemic control in a low-income population with type 2 diabetes. Diabetes technology \& therapeutics 13(3): 335-341

16. Peyrot M, Rubin RR, Kruger DF, Travis LB (2010) Correlates of insulin injection omission. Diabetes care 33(2): 240-245. 


\section{ISSN: 2574-1241}

DOI: $10.26717 / B J S T R .2020 .30 .004990$

Thamara Dilhani Amarasekara. Biomed J Sci \& Tech Res

(c) (i) This work is licensed under Creative (c) Commons Attribution 4.0 License

Submission Link: https://biomedres.us/submit-manuscript.php

$\begin{array}{ll}\text { BIOMEDICAL } & \text { Assets of Publishing with us } \\ \text { RESEARCHES } & \text { Global archiving of articles } \\ & \text { - Immediate, unrestricted online access } \\ & \text { - Rigorous Peer Review Process } \\ & \end{array}$

